\title{
Secretos y supercherías en una comedia de Lope de Vega: El gran duque de Moscovia
}

\section{Secrets and Tricks in a Lope de Vega's Comedy: El gran duque de Moscovia}

\section{Luis Iglesias Feijoo}

Universidad de Santiago de Compostela ESPAÑA

luis.iglesias.feijoo@usc.es

[Hipogrifo, (issn: 2328-1308), 5.1, 2017, pp. 277-291]

Recibido: 13-05-2016 / Aceptado: 23-05-2016

DOI: http://dx.doi.org/10.13035/H.2017.05.01.18

Resumen. Esta comedia de Lope de Vega no ha merecido mucha atención crítica. Casi todos los trabajos se han centrado en la fecha de su redacción, siendo hoy el año de 1613 el que suele aceptarse. Aquí se propone el de 1608. Se lleva a cabo también un intento de considerar su segmentación en cuadros para acercarse a su estructura.

Palabras clave. Teatro, Siglo de Oro, Lope de Vega, El gran duque de Moscovia, fecha, fuentes, estructura.

Abstract. This comedia by Lope de Vega has received few criticism until now. Most of the studies about this play deal with its date: 1613 is commonly accepted as the year of composition. This article tackles this problem and defends the year 1608 by establishing the connection between the comedia and its sources. This article also explains the segmentation and structure of this comedia.

Keywords. Theatre, Golden Age, Lope de Vega, El gran duque de Moscovia, Date, Sources, Structure. 
En octubre de 2014 pronuncié una ponencia en un simposio sobre el tema «Mentiras y secretos en el teatro hispánico del Siglo de Oro», celebrado en la Stony Brook University, de la State University of New York. Ahora quiero dedicarla a la memoria de mi buen amigo Francisco Ruiz Ramón, que pasó la mayor y mejor parte de su trayectoria académica en el sistema universitario norteamericano en el que fueron pronunciadas mis palabras, acogidas a un título que se explica por el tema de la reunión en la que se oyeron en versión más reducida.

$$
\star * *
$$

La fecundidad literaria de Lope de Vega es bien conocida'. En el terreno del teatro, sus comedias abordan los más diversos temas y se ubican en épocas muy diversas. Hoy nos interesa una obra que sorprende dentro de las suyas, ya que no es fácil descubrir cuáles fueron las razones que le llevaron a componerla. El gran duque de Moscovia y Emperador perseguido trata un asunto entonces de la máxima actualidad, si bien ubicado fuera del marco hispánico; se trata de la historia del conocido como falso Demetrio, esto es, la del supuesto hijo del zar Iván el Terrible, que habría sido asesinado en su niñez. Tras el acceso al poder de Boris Godunov, un supuesto Demetrio reclama el trono y se enfrenta a él, de manera que se convierte en zar en 1605.

Las noticias del caso ocurrido en las lejanas tierras rusas se extendieron por Europa y llegaron también a España, transmitidas sobre todo por jesuitas que, bajo la inspiración del papado, otearon una posibilidad de convertir al catolicismo el territorio entonces de religión ortodoxa. Sin embargo, las intenciones de Lope al escribir su comedia resultan difíciles de adivinar, fuera del carácter agitado de los hechos, en los que debió de ver latentes posibilidades para convertirlos en una acción dramática atractiva. Ahora bien, la obra apenas ha merecido atención en sí misma, pues la mayoría de quienes se han ocupado de ella se han centrado tan solo en el estudio de sus fuentes históricas y en la fecha de su composición, aspectos asimismo estrechamente relacionados.

Ese fue el caso de Menéndez Pelayo, quien, aparte de aludir a sus inexactitudes, explica que hubo de basarse en relaciones escritas, como la de Barezzo Barezzi, además de aprovecharse de informes orales; destaca que en la obra Demetrio es heredero legítimo y no un impostor, y que en el desenlace reina en Rusia, siendo así que el personaje real murió en mayo de 1606. Por ello deduce que la noticia de su muerte no era conocida aún en España. Ahora bien, todo lo que tiene que decir sobre el aspecto teatral de la comedia es que ha llegado a nosotros muy estragada y con intervenciones de ajena mano. Pero este era un recurso muy manido para explicar obras lopescas que no coincidían con los cánones de la crítica decimonónica. Aparte de ello, se señala que «la marcha de la acción es novelesca 
e interesante; el diálogo muy vivo y libre de afectaciones; hay frases de gran efecto dramático». No parece un análisis muy profundo².

Como en la comedia salen dos personajes Ilamados Belardo y Lucinda, Américo Castro aceptaba la fecha sugerida por don Marcelino hacia 1606, porque en el texto hay un elogio de Lucinda, que la ubicaría antes de 1608, año en que terminan las referencias a ella ${ }^{3}$ :

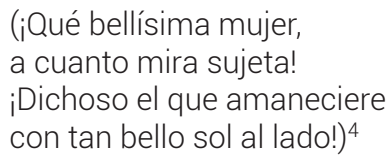

Pero, de un lado, Belardo es aquí padre de Lucinda, y además los versos no elogian a esta, sino a Margarita, la hija del conde Palatino. Como quien los dice es Demetrio, la cita no prueba nada ${ }^{5}$. En todo caso, incluir el elogio de otra dama estando presente el personaje de una Lucinda llevaría a pensar que Lope no estaba entonces en el punto álgido de sus amores con la Luján.

En 1932 Gertrud von Poehl señaló que Lope no utilizó como fuente de los hechos la Relazione jesuítica publicada por Barezzi en 1605, ya conocida por Menéndez Pelayo y que llegó a ser atribuida al jesuita Antonio Possevino, que había estado como enviado papal en Moscú y se mantenía al tanto de los hechos de aquella corte, sino una traducción española, obra de otro jesuita, Juan Mosquera, aparecida en Valladolid en 1606, por Andrés de Merchán, que es en realidad una adaptación amplificada, con el título Relación de la señalada y como milagrosa conquista del paterno Imperio, conseguida del Serenísimo Príncipe Juan Demetrio, Gran Duque de Moscovia, en el año de $1605^{6}$. No hay duda respecto a su empleo por el dramaturgo, pues en su comedia recoge aspectos que no figuraban en el original italiano. Ahora bien, de la obra en sí la estudiosa solo apunta su «sentimentalismo algo vulgar» y la «suave tonalidad romántica», para concluir que la historia del falso Demetrio «pasaba al teatro para cobrar en él coherencia y sentido moral, sobre todo para enseñar deleitando», como si Lope fuera partidario de la literatura docente

2. Menéndez Pelayo, 1949, vol. II, pp. 333-342. El estudio se publicó como prólogo a la obra en la edición de la Real Academia Española: Lope de Vega, Obras, vol. VI.

3. Castro, 1918, p. 279; puede verse como apéndice en Castro-Rennert, 1968, pp. 401-430; ver p. 420. No cambia nada sustancial Bruerton, 1937; ver p. 310.

4. Vega, Comedias, Parte VII, vol. I, p. 526. El gran duque de Moscovia se cita por esta edición, realizada por Milagros Villar, 2008, pp. 457-587. En adelante, las referencias a la paginación se incluirán sin más en el texto.

5. Siguiendo a Castro, también se engañaba Fichter, 1924, p. 273, al pensar que estos versos se referían a Lucinda.

6. Hay ejemplar en la Biblioteca Nacional de España: R/22201. Está referenciado en Wilkinson y Ulla Lorenzo (ed.), 2015, vol. III, p. 1641. Ver ahora la web del Proyecto Iberian Book: iberian.ucd.ie. Todas las citas posteriores de este y otros textos del XVII se regularizan en su ortografía. 
en la escena o como si la tomase de tribuna para predicar al público. Cierto que al menos añadía que era una «biografía dramática sumamente movida y animada»?

Parecía aclarado el problema, pero muy poco después van Praag, tras destacar con oportunidad que la publicación de la obra en la Parte Séptima de las comedias en 1616 (aunque ya con fecha de 1617) no se debió a iniciativa de Lope, añade que, en su opinión, el autor no solo leyó la Relación de Mosquera, sino también la Cuarta Parte de la Historia Pontifical y Católica, con la que Luis de Bavia prosiguió las dos primeras partes de Gonzalo de Illescas, y aparecida en Madrid en 1613, por Luis Sánchez ${ }^{8}$. Por lo tanto, la obra se habría compuesto en fecha más tardía de lo sospechado antes ${ }^{9}$, aunque en realidad lo único que prueba es que Bavia usó a Mosquera y leyó acaso otras fuentes comunes.

Tras alguna otra aportación poco decisiva, como la de Vernet en 1949, que apuntaba la posibilidad de que Lope hubiera tenido acceso a informes orales ${ }^{10}$, Ilegamos a la monografía de Brody, la única que ha dedicado una atención detallada a la comedia que nos ocupa ${ }^{11}$. En lo que se refiere a las fuentes, secunda y amplía las tesis de van Praag y considera que es seguro que Lope usó tanto la Relación de Mosquera como la Cuarta parte de la Historia de Bavia. Pero si los argumentos de van Praag eran poco convincentes, tampoco los ejemplos que muestra Brody pasan de una probabilidad algo remota, pese a que la moderna editora de la obra en la serie de Prolope lo acepta sin ambages ${ }^{12}$.

En efecto, enumera hasta doce motivos para verificar que Lope leyó a Bavia, pero la mayoría son de muy poca utilidad y no prueban nada: la referencia a Tácito en boca del Boris lopesco es mostrenca; a Demetrio niño se le llama «niño» (!), cosa poco sorprendente: también lo hace la Relación de Mosquera (fol. Gr); Bavia no emplea la frase «tiranizado sus estados», como sostiene Brody, para hacerla coincidir con el verso 972 de Lope («tiraniza los estados» ${ }^{13}$ ), sino que señala que su ayo le impulsa a «restituirse en el estado paterno, tiranizado por Boris» (fol. 380), pero ya Mosquera califica a Boris de 'tirano' no menos de once veces (dos en fol. $6 \mathrm{~V}$, tres en fol. $7 r$, una en $9 r$, en $9 v$, en $10 r$ y en $14 r$ y dos en $15 v$ ) y alude a que era «tiránico y cruel» (fol. $7 r$ ), aparte de referirse a su 'tiranía' (fols. 7v, 8v y 13v). El volumen del ejército de Boris Godunov lo determina con precisión Mosquera (fols. 14r y 15v): «pasaba de cien mil hombres», dato que repite Lope: «Ya con cien mil hombres

7. Poehl, 1932, pp. 56, 57, 61 y 62, sucesivamente. Años después no se ha avanzado mucho, pues Brody, 1972, p. 53, habla de su «quickly moving romantic stravaganza and baroque chiaroscuro».

8. Se puede leer digitalizada en la Biblioteca Digital Hispánica de la BNE:< http://bdh-rd.bne.es/viewer. vm?id=0000137319\&page $=1>$

9. J. A. van Praag, 1937.

10. Vernet, 1949.

11. Brody, 1972, pp. 52-140.

12. Milagros Villar, en la ed. cit., Lope de Vega, Comedias, Parte VII, vol. I, p. 465. No deja de ser curioso que el editor general de ese volumen, Di Pastena, 2008, I, p. 26, feche la obra hacia 1606.

13. Lope de Vega, Comedias, Parte VII, vol. I, p. 505; por cierto que Brody, 1972, p. 63 transcribe el verso «tiranizo los estados». Aunque sigue la edición de la BAE (Vega, Comedias escogidas, p. 262), aquí Hartzenbusch lee como la moderna edición crítica. 
marcha / Boris» ${ }^{14}$; que Bavia use las palabras «puerto», «industria» para indicar la agudeza o «alborotar» para referirse al pueblo descontento son pruebas muy débiles... Por ejemplo, Mosquera (fol. 14v) también emplea el último verbo citado: «Con estas nuevas se alborotó la gente del ejército».

En verdad, si Lope hubiera escrito El gran duque de Moscovia después de 1613, es decir, tras leer el cuarto tomo de la obra de Bavia, no se entiende por qué razón culmina la comedia con el triunfo de Demetrio, cuando en la Historia Pontifical se relata su muerte. De escribir en 1613 o 1614 tenía ya poco sentido acudir a la relación de Mosquera. ¿Qué habría llevado a nuestro autor a escoger para la escena un tema como este, de saber que el infortunado Demetrio solo había estado un año en el poder? Por el contrario, todo conduce a pensar que Lope escribe cuando aún se desconoce en España el trágico fin del Duque, que en todo caso no debió de ser divulgado de inmediato y se vio envuelto en dudas, sospechas, falsificaciones y supercherías, como la creencia de que no había sido asesinado, sino que pudo escapar y reaparecer, eso sí, encarnado en un segundo falso Demetrio. Parece que hasta fines de 1608 el Papado no asumió del todo la idea de que en efecto el Duque había muerto.

Además, la insistencia de Bavia en que la subida de Demetrio al trono era ocasión para que Moscovia se convirtiese al catolicismo, impulsada por el apoyo que Polonia ofreció a Demetrio, se ignora de todo punto en Lope. Más aun, el dramaturgo hace de Rusia un país ya obediente al Papado, y así oímos a Boris proclamar en el acto tercero ${ }^{15}$ :

$$
\begin{aligned}
& \text { Al Papa quiero escribir } \\
& \text { Que soy príncipe clemente } \\
& \text { y católico, y pedir } \\
& \text { que el rey Sigismundo intente } \\
& \text { este disinio impedir. }
\end{aligned}
$$

Ahora bien, ello no quiere decir que Lope hubiese compuesto la obra al mismo momento de aparecer la Relación de Mosquera, es decir, en 1606. La historia del personaje pudo estar rodando un tiempo por su cabeza, y proceder a escribirla uno o dos años después, cuando aún no estaba confirmada su muerte. Al respecto, es sumamente curioso que en 1608 se publicara la Tercera parte de la Historia Pontifical de Bavia, pues en ella pudo hallar el dramaturgo algunos elementos que le recordaran los sucesos moscovitas y algunos de sus antecedentes. En esa tercera parte se cuenta - siguiendo, según declara, a Posevino- cómo Juan Basilio -es decir, Iván el Terrible- abofetea a su nuera («ciegamente colérico dio un bofetón a la buena señora»), esposa de Juan, su hijo primogénito y preferido, al que de inmediato da muerte brutal con un golpe de su cetro, que es un bastón herrado («Con el mesmo báculo hirió el Duque al Príncipe en la cabeza mortalmente»), todo lo cual

14. Lope de Vega, Comedias, Parte VII, vol. I, p. 558, vv. 2677-2678. Lo repite en v. 2918 (p. 565) y v. 2964 (p. 567). Brody, 1972, p. 63, alude a que Lope saca de Bavia que los ejércitos tenían «desigual número» 15. Lope de Vega, Comedias, Parte VII, vol. I, p. 550, vv. 2420-2424. Cierto que en esto también se separa de Mosquera, que celebra que con Demetrio Moscovia se pueda convertir al catolicismo. 
lo escenifica Lope en la primera jornada, si bien añadiéndole elementos ficticios. Además, en esa tercera parte de la Historia Pontifical se menciona también que el mismo zar dio una bebida a su hijo Teodoro que le turbó el juicio, envenenamiento también aprovechado por Lope. Y, en fin, ahí se señala que este Teodoro era padre de Demetrio, lo mismo que en la comedia ${ }^{16}$.

Sin embargo, en la Cuarta parte de la Historia Pontifical, Bavia rectifica y deja claro que Demetrio no es nieto, sino hijo de Juan Basilio, con lo que resulta hermano de Teodoro: este casó «con una señora principal de su tierra. Piensan algunos que tuvo en ella un hijo llamado Demetrio; pero es muy sin fundamento; porque Demetrio era hijo de Juan Basilio, hermano de Teodoro, habido en diferente madre» ${ }^{17}$. Con esta donosa desenvoltura Bavia omite que uno de los que afirmaban que Demetrio era hijo de Teodoro era él mismo en el tomo anterior. Todo conduce, pues, a suponer que Lope no consultó la cuarta parte de Bavia, pues no hubiera mantenido semejante parentesco, denunciado como falso. Él, que sin duda había conocido la relación de Mosquera, acaso refrescó sus ideas y concibió el propósito de escribir una comedia al leer la Tercera parte de Bavia, en la cual se supone que Demetrio sigue vivo, con lo cual la obra puede ser del año 1608. Con todo, fueran cuales fuesen las fuentes empleadas, Lope decide usarlas a conveniencia y alterar lo que le place: añade intrigas amorosas, hace de Teodoro el hijo mayor, en vez de a Juan, es decir, emplea la libertad creadora, porque escribe teatro, y no crónica.

Morley y Bruerton sugieren también una fecha anterior a 1613, aunque no apunten a ese año citado, sino al de 1606?, con interrogación ${ }^{18}$. La datación en 1608 resulta muy coherente con el conjunto de comedias que se editan en la Séptima Parte. Como es bien sabido, la preparación de este volumen se vio obstaculizada en principio por el pleito que emprendió el propio Lope en 1616 contra Francisco de Ávila, que fue quien las recopiló y obtuvo privilegio para imprimirlas ${ }^{19}$. Esta acción procesal del autor de los textos nos ha permitido conocer bastante bien los entresijos de la preparación de los volúmenes VII y VIII de comedias del Fénix. Para lo que nos importa, sabemos que El gran duque de Moscovia era de Baltasar de Pinedo, a quien fue adquirida con otras once, por el ridículo precio de 50 reales todas ellas. ¿Cómo así? Porque se trataba de obras viejas, que habían «gastado su vida en las

16. Luis de Bavia, Tercera parte de la Historia Pontifical y Católica, ver el cap. LXXIII, pp. 260-264; las citas, en p. 263. Puede leerse en la Biblioteca Digital Hispánica: < $\underline{\text { http://bdh-rd.bne.es/viewer. }}$ vm?id=0000086144\&page=1> [9/1/2017]. Aunque también Mosquera, fol. 5r, menciona la muerte de Juan por un golpe de su padre con el «bastón herrado», no alude al origen de la disputa de Basilio con su nuera, dice solo que riñeron padre e hijo «por causa de su mujer», mientras Bavia menciona el «bofetón», ya citado, que aparece literalmente en la acotación de la obra de Lope. En cambio, en la Cuarta parte Bavia no habla de ningún bofetón

17. Luis de Bavia, Cuarta parte de la Historia Pontifical..., cap. LXXXVI, p. 378. Algo después en la misma página insiste, al referir que Boris «quiso dar la muerte a Juan Demetrio, que (o por hijo de Teodoro, como algunos dicen falsamente, o por su hermano, como otros creen y mejor)...».

18. Morley y Bruerton, 1940, pp. 25, 39, 64 y 80. Nada cambia en Morley y Bruerton, 1968, pp. 60, 87, 123 y 148, aunque actualizan la bibliografía. No añaden nada al respecto Canonica, 1994, ni Smotki, 2003.

19. Dio cuenta del pleito González Palencia, 1921. 
tablas», como dice Enrico Di Pastena ${ }^{20}$. Aunque la Séptima Parte no está conformada solo por comedias que pertenecieron a Pinedo (un total de ocho), sino que se sumaron otras compradas a Luis de Vergara o de otra procedencia, lo que resalta es que la mayoría de las que venían del primer autor datan de los años centrales de la primera década del siglo XVII, aunque algunas son incluso anteriores a $1601^{21}$. Solo el caso algo extraño de El villano en su rincón parece ser relativamente moderna, de 1611, pero la fecha que casi por inercia hoy se le atribuye puede y debe ser discutida, para atrasarla unos años 22 .

En suma, todo indica que El gran duque de Moscovia es una comedia escrita por Lope de Vega años antes de ser vendida a Ávila por Pinedo, el autor que la poseía - es decir, el autor de teatro que se la había comprado a Lope-, por lo que habría ya corrido por los corrales españoles durante quizá ocho años, de manera que podía desprenderse de ella sin mayor dolor, aunque con bien menguada ganancia.

Dejemos este algo enfadoso tema y acerquémonos a la obra en sí misma. Lo primero que cabe preguntarse es qué vio Lope en el asunto del falso Demetrio que le impulsara a redactar tres actos en torno a él. La primera respuesta es clara: para Lope no hay 'falso Demetrio', pues en ningún momento se duda de que el personaje es el legítimo heredero del trono. La incógnita ni se plantea, aunque Lope no podría ser del todo ignorante de las dudas que levantó el personaje histórico que aparece en la corte de Polonia reclamando ser el heredero del Ducado de Moscú.

No han faltado sugerencias acerca del deseo del dramaturgo de aludir a sucesos contemporáneos a través del personaje elegido. En tal sentido, fue sin duda Jack Weiner quien caminó más lejos, pues según su hipótesis hasta cuatro motivos habrían impulsado a Lope para llevar el caso a la escena: la alusión a la muerte del príncipe don Carlos por su padre Felipe II, la usurpación del trono de Portugal por este mismo rey, el tema del sebastianismo derivado de ese hecho y, en fin, la alusión crítica a la dejación en manos de los validos del gobierno del Estado ${ }^{23}$. Aparte de que el intento de descubrir alusiones políticas a guisa de parábola en las comedias del teatro clásico español es tarea que ha agotado su recorrido en los últimos años, con muy poco éxito, parece excesivo el número de referencias que se creen descubrir en nuestra obra. La mención del caso de Portugal es explícita en la obra de manera inequívoca, pero para secundar la resolución de Felipe II (pp. 513-514, vv. 1236-1247):

$$
\begin{aligned}
& \text { - Alguno, por levantar } \\
& \text { a Moscovia contra mí, } \\
& \text { dice que vive [Demetrio]. } \\
& \text { - } \quad \text { ¿Es ansí? } \\
& \text { - Ejemplos os puedo dar, }
\end{aligned}
$$

20. Di Pastena, en Lope de Vega, Comedias, Parte VII, vol. I, p. 13. Aquí se encuentra resumida a la perfección toda la historia del pleito y sus problemas.

21. Ver también García Reidy, 2007 y 2013, pp. 332-336.

22. Las supuestas alusiones que se han utilizado para fechar esta comedia resultan muy dudosas, pero merecen ser tratadas en un trabajo específico, de próxima publicación en el Homenaje a Aurora Egido. 23. Weiner, 1978. 


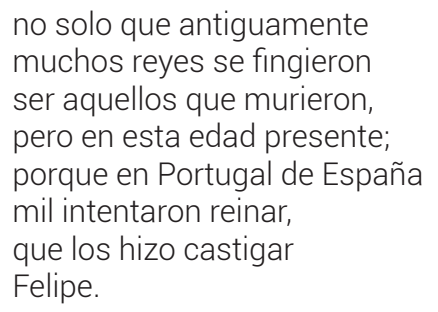

No parece que quepa derivar de aquí la mínima alusión crítica al caso que se menciona ${ }^{24}$. Y del resto puede concluirse lo mismo.

Debió de ser sin más la compleja intriga existente en la historia de Demetrio lo que movió a Lope a dramatizarla. Cabe subrayar que se trata de un tema del todo contemporáneo, pues, como quedó dicho, Lope no parece haberse enterado de que el fugaz gobierno de Demetrio duró tan solo un año y acabó con su muerte. De conocerla, no habría dejado de aprovechar la noticia para presentarlo como un caso de lo fugaz de las victorias humanas o un ejemplo de las caídas de los hombres ilustres. Pero de ello no hay ni rastro en la comedia. Y, en cambio, sí aparecen elementos poco frecuentes en su teatro: multitud de personajes, hechos sangrientos en escena, violencia, persecuciones, poderosos tiránicos, vesania, horror y triunfo final de la justicia, al menos tal como se han presentado los hechos.

Si se prescinde de la sospecha de que hubo de abrigar alguna duda respecto a la entidad real de Demetrio, nada de superchería aflora en la presentación en escena. El desfile de personajes (más de treinta) es de lo más sorprendente; aunque algunos actores pueden hacer lo que en el argot teatral se conoce como 'doblar papeles', es decir, que un cómico represente a personajes diferentes que no coinciden juntos, lo cierto es que la compañía de Pinedo debió de verse obligada a solicitar refuerzos para poner sobre las tablas esta comedia. Su construcción está dominada por el vértigo de la acción y la sucesión de peripecias. Y, por cierto, pese a sus altibajos, debe de ser obra entera de Lope, y no parece que haya entrado otra mano a manipularla, como demuestra que la versión que aparece en la Séptima Parte es sensiblemente la misma que figura en un manuscrito hoy de la Biblioteca Nacional de España ${ }^{25}$ y que resulta independiente, como ha probado la edición crítica llevada a cabo por Milagros Villar para Prolope.

Si prestamos atención a su estructura, tan desatendida hasta ahora, puede observarse que el acto primero se divide en cuatro escenas de muy desigual extensión. La primera, la más larga, no solo se limita a presentar los hechos y a los

24. Smotki, 2003, p. 729, cree que se ha manipulado la historia rusa para aludir al sebastianismo. No parece haber nada de eso.

25. Aunque alguna vez se ha escrito que está fechado en 1613 (por ejemplo, Castro, 1918, p. 279, si es que se refiere a este manuscrito, como parece), ni la moderna editora de Prolope lo atestigua, sino que solo apunta: «Probablemente del siglo XVII» (Vega, 2008, I, p. 466), ni lo indica el Catálogo de Paz y Mélia, 1934, p. 398, ni lo señala García Reidy, 2013, pp. 327-328. 
personajes, sino que incluye ya aspectos decisivos de la trama. Se extiende entre los versos 1 y 759, y en ella cabe diferenciar varias subescenas ${ }^{26:}$

1a (1-120, quintillas): salen Juan Basilio, es decir Ivan, escrito al modo de la época (esto es, Iván el Terrible) y su hijo Teodoro, definido ya en la acotación inicial como «mentecato», quien recibe una catarata de insultos de su padre: «Monstruo de naturaleza», «vil, fabulosa cabeza», «Hombre falto y ignorante, / rudo y villano grosero», «ilnfame, medio mujer!» (p. 477), «tonto», «bestia» (p. 478). En escena está también Demetrio niño, que razona a la perfección e interviene en favor de su padre ante su abuelo. Este deja la escena con una profecía: «Según la cólera mía, / temo que aqueste bastón / le ha de dar la muerte un día» (pp. 479-480), aunque antes Teodoro pronuncia otra: «Todo es celos, / todo es querer dar a Juan, / tu hijo, aqueste ducado. / Pues tus ojos no verán / ese tu Juan coronado» (p. 479).

$1 b$ (121-243, quintillas): Demetrio, con sus doce años, se muestra muy redicho aconsejando a su padre, que exclama: «y ved quién me enseña a mí!». Tras unas digresiones sobre caballos, perros y trajes, con ribetes cómicos, pero que muestran la lucidez que a veces descubre Teodoro, sale este de escena con el sastre.

1c (243-397, acaban las quintillas, sigue romance en -eo): sale Cristina, mujer de Teodoro y madre de Demetrio, con Lamberto. Ella hace relación de los hechos pasados y pone en antecedentes al público de la situación presente: a Teodoro, el hijo mayor, le han dado unas hierbas los partidarios de Juan para que perdiera la razón y con ello la posibilidad de heredar el Ducado. Temerosa por la vida de su hijo, anuncia el plan de apartar en secreto a Demetrio de la corte y enviarlo a un castillo con Lamberto, «caballero tudesco», para que reciba la educación propia de un príncipe en unión de un hijo del alemán de su misma edad. Se acumulan las profecías, que siguen abriendo las expectativas en el público: «tú sabrás cobrar tu reino», dice su madre a Demetrio. Lamberto, por su parte, acepta el papel de ayo y casi el de padre sustituto: «seros tan leal prometo / que venda mi propia sangre / por vos» (p. 487). Se van de escena el niño y su nuevo maestro.

1d (398-429, redondillas): sale Isabela, mujer de Juan, que discute brevemente con Cristina; esta la acusa de estar resentida por no haber tenido un hijo.

1e (430-759, redondillas, más endecasílabos blancos): se encadenan los hechos. Un breve monólogo de Isabela ofrece una perspectiva bastante insólita: ya que su marido Juan no puede darle hijos, piensa en concebirlos con otro hombre. Y al instante entra un candidato, Rudolfo, que está enamorado de ella. Como la dama le da esperanzas, se arroja a abrazar sus pies, escena que descubre el duque Basilio. Ello desencadena el temporal. El duque cree que el honor de su hijo está en peligro, y aunque Isabela pronuncia las palabras clave para asegurar lo contrario ("Yo soy quien soy», p. 492), su arrogancia hace que Basilio le dé un bofetón. Ante la injuria ella da voces, comparece su marido Juan, Isabela acusa a su suegro de querer deshonrarla, Juan se encara con su padre y este le da tal golpe con el bastón

26. No es momento de entrar ahora en la discusión de si importa más el escenario vacío o la métrica para la segmentación de la comedia española. Ambos deben ser considerados y aquí es evidente que Lope prosigue en varios momentos con la misma estrofa cuando la escena ha quedado vacía. 
que hace de cetro que lo mata en escena. Se llega así a un clímax de tragedia cercana al grand guignol, poco frecuente en Lope. Salen todos, menos Teodoro, que contempla la llegada de su mujer con su hermano Boris, es decir, Boris Godunov (Boris Hoduno, lo llama la Relación de Mosquera, fol. 5v). Comentan la situación y traen la noticia de que el suceso ha afectado tanto a Basilio que está a las puertas de la muerte. Cristina manifiesta su proyecto: será su hermano Boris quien actúe de gobernador de todos los estados en nombre de Teodoro hasta que toque el cetro a Demetrio. Pero en un aparte, Boris revela su plan -otro anuncio más- de dar cuenta de su sobrino.

Frente a esta secuencia ininterrumpida de sucesos acumulados, las otras tres escenas de este acto son breves y resultan por ello casi vertiginosas. La segunda (versos 760-831, redondillas) traslada la acción al castillo de Lamberto donde es acogido Demetrio para ser educado con el hijo del huésped, César, de su edad. Ha transcurrido, pues, muy poco tiempo. Está también presente un personaje episódico, que acompañará desde este momento al protagonista, Rufino, «un gentilhombre español» (v. 775). Su papel es el de mero adyuvante, pero su naturaleza es harto extraña, pues, pese a su nobleza, en algunos momentos asumirá rasgos específicos propios del gracioso. Las profecías o anuncios se suceden: Lamberto asegura que si fuera necesario sacrificar a su hijo por Demetrio, lo haría (pp. 499-500), y el propio César proclama: «y yo moriré por vos» (v. 831). Se adensan, por tanto, las sombras que esos augurios, casi siempre fatales, van sembrando.

La escena tercera (versos 832-911, octavas reales) trae la noticia de que el gran duque Basilio es muerto y Boris se ha hecho con el poder, pero con pretensiones de quitar de en medio a sus rivales posibles. Por ello confiesa a su confidente Rudolfo su proyecto de matar a Demetrio. Los planes son escuchados por el español Rufino, que aparece por la corte sin saberse muy bien por qué ni para qué. Descubierto, corre gran peligro, del que se salva haciéndose pasar por sordo y tartamudo, grotesco paréntesis no demasiado coherente. Para asegurarse la lealtad de Rudolfo, encargado del plan de matar a Demetrio, Boris le promete que la viuda de Juan, Isabela, será suya.

En fin, la escena cuarta (versos 912-1049, redondillas, más romance en -eo) culmina la primera jornada con tintes luctuosos. Tras un inicio inocente en el castillo de Lamberto, en el que juegan con espadas Demetrio y César, marchan los niños a acostarse. Rufino llega con las malas nuevas del proyecto de Boris, y al momento se personan los soldados con Rudolfo. El sacrificio de Lamberto es máximo: hará que su hijo sea asesinado como si fuera Demetrio, al que se lleva en su huida para salvarle la vida: «Estos son, tiempo es agora, / generosos pensamientos, / de dar mi sangre a un tirano / por dar un rey a estos reinos» (p. 506). Y el anuncio de la llegada de Demetrio al poder lo repite aún en el último verso del acto, a él dirigido: «Él te volverá tu reino» (p. 508). Debe señalarse que la muerte del niño César no ocurre fuera de la vista del público, sino que este presencia cómo se corre la cortina del foro para contemplarlo durmiendo en una cama, cómo se acercan los soldados, le echan las manos al cuello y lo ahogan hasta morir, truculencia nada frecuente en la escena española del tiempo (pp. 506-507): 


$$
\begin{aligned}
& \text { - Apriétale presto el cuello. } \\
& \text { Ahóganle } \\
& \text { - ¡Ay, que me matan! } \\
& \text { - ¿Espiró? } \\
& \text { - ¡Jesús! } \\
& \text { - Yprieta } \\
& \text { - Y Ya es muerto. }
\end{aligned}
$$

Los actos segundo y tercero presentan una mayor viveza, la acción se dispara, cambian los lugares en que se desarrolla, pasan muchos años, de manera que resulta lógica la división de cada una de las jornadas en siete escenas. La primera del acto segundo (versos 1050-1223, redondillas, más romance en -oa, más redondillas con un soneto englobado) presenta a Demetrio, "ya hombre», según la acotación inicial. Lamberto está tan falto de fuerzas que casi va a morir sobre el tablado. Tras acometerle «Bascas de muerte», según otra didascalia (p. 511), es sacado piadosamente del escenario por el español Rufino para que muera en su cama. No está del todo claro por qué evita Lope a los espectadores la visión de su final cuando en el acto anterior no ahorraba las que hemos considerado.

Sin embargo, por muy desfallecido que esté, Lamberto ha tenido tiempo de 'pegarse' cien versos de romance (1070-1169) en los que resume «tantas cosas» que han sucedido en el intervalo, aunque algunas eran ya conocidas («las relaciones piden los romances ${ }^{27}$ ): él ha sacrificado a su hijo César, haciéndolo pasar por Demetrio, Boris puso fuego al castillo de Lamberto para encubrir el hecho, provocando la muerte de Tibalda, la esposa del caballero alemán, Teodoro, el duque nominal, ha muerto también, su esposa Cristina, madre de Demetrio, entró en un convento, Boris es emperador de Rusia desde hace diez años y, en fin, el agonizante Lamberto, que ha recorrido en ese lapso «varias provincias» (p. 511), exhorta al joven a que recobre el «paterno imperio, / que Dios te dará victoria», nuevo anuncio de futuro que despierta las expectativas generales. Pero Demetrio duda, pronuncia un notable soneto ( Nací rey, pobre soy, secreto vivo», p. 512), en el que alude a la igualdad general ante la muerte, y decide abandonarlo todo y hacerse fraile en un monasterio.

La breve escena segunda (versos 1224-1303, continúan las redondillas) muestra a Boris y su esposa Orofrisa comentando el rumor extendido de que Demetrio vive. El zar razona que solo puede ser una superchería, y es aquí cuando comenta el caso de Portugal, pero para acallar murmuraciones decide visitar todas sus tierras.

La escena tercera (versos 1304-1507, redondillas) ofrece en principio un paréntesis cómico con Demetrio y Rufino de frailes. El primero mantiene su idea de rechazar ambiciones («ya no quiero otra corona», p. 516). En eso se anuncia la visita del Gran Duque; cuando este ve al disfrazado fraile, tan igual a Demetrio, se turba y sugiere al Prior que lo mate. Pero el joven, consciente del peligro, decide colgar los 
hábitos y huir, no sin reflexionar que está en peligro, rechace o no la idea de ser rey (p. 521):

\author{
Parece más ley, \\ por reinar pasar tormento; \\ mas ya paso los que siento \\ pues que huyo de ser rey.
}

La muy breve escena cuarta (versos 1508-1559, siguen las redondillas) cambia el marco y las referencias: los huidos Demetrio y Rufino visten de segadores y topan con unos villanos, Belardo, Lucinda y Febo. Es esta mero prólogo para la escena quinta (versos 1560-1753, alternan los endecasílabos blancos con redondillas, más una canción), en la que aparece un personaje importante a partir de ahora: el Conde Palatino y su hija Margarita andan a caza y se cruzan con los anteriores, entre ellos Demetrio. Este queda prendado de la noble joven y anuncia un plan que muestra el cambio de sus aspiraciones: entrará a servir al Conde, amigo del rey de Polonia, a fin de revelar su identidad y apoyarse en ellos «para hacer guerra al traidor /... / que usurpa el imperio mío» (p. 527). Pero para pasar desapercibido hasta el momento oportuno, servirá en las cocinas y así harina y carbón ocultarán su rostro.

La escena sexta (versos 1754-1832, endecasílabos blancos) marca un contrapunto alternante: Boris, que lleva 16 años en el poder, castiga con la muerte al astrólogo que va difundiendo por su reino el rumor de que Demetrio vive. El acto termina con la séptima escena, que conecta con lo anunciado en la quinta (versos 1833-2084, redondillas). Demetrio y Rufino son pícaros de cocina en el palacio del Conde Palatino e inician un paso cómico, que deja lugar a la entrada de Margarita, a la que se declara sin rodeos el pretendiente Demetrio.

El acto tercero comienza con una larga escena (versos 2085-2379, quintillas, más romance en -eo, endecasílabos blancos y regreso a las quintillas) entre el Conde y el Rey de Polonia, en que este recibe la nueva de que Demetrio vive y está a la espera de ser recibido. Tras unos titubeos de bastante frialdad sobre si debe cambiar de traje y ha de tomar asiento o no, Demetrio se dedica a hacer una relación, por supuesto en romance, de todo lo pasado. Al rey polaco sin duda le viene bien enterarse de los hechos, pero el público los conoce de sobra; acaso la función de este romance sea ordenarlos en la mente del espectador ahora que comienza un nuevo acto. Pero aún se añade un colofón en el que Rufino actúa definitivamente en papel de gracioso.

La escena segunda (versos 2380-2494, siguen las quintillas) presenta a Boris y su esposa al recibir la noticia de que Demetrio vive, está en Polonia y cuenta con el apoyo de este país y con el fervor del pueblo. Para atajar los problemas piensa en conseguir el favor del Emperador, del Papa y de varios países y envía a Polonia a Rudolfo con una embajada, aunque entonces llega el aviso de que el pretendiente ha reunido ya un ejército de cincuenta mil hombres.

La escena tercera (versos 2495-2684) tiene dos momentos. En el primero (redondillas) Margarita y el Rey de Polonia despiden a Demetrio y en el segundo (ter- 
cetos más redondillas) el monarca recibe al instante a Rudolfo, el enviado de Boris. Ante la queja por haber dado acogida al pretendiente, el Rey actúa de manera sorprendente, pues disimula y finge haber sido engañado y anuncia que dará orden de que corten a Demetrio la cabeza, extraña actitud en un monarca.

La extensa escena cuarta (versos 2685-2948, alternan endecasílabos blancos y quintillas, para acabar en redondillas) sirve para dibujar la clemencia de Demetrio. En primer lugar perdona la vida a Eliano, traidor comprado por Boris, que planea una añagaza en la que toma parte Finea, para que esta seduzca al pretendiente y él pueda matarlo cuando esté «en su deleite ocupado» (p. 559). Pero descubierto el plan, Demetrio revela su magnanimidad y perdona a Eliano, con lo que se subraya la diferencia que existe entre él y Boris. En un segundo momento aparece Rudolfo con la carta del rey de Polonia, en la cual, lejos de ordenar que maten al pretendiente, advierte de la traición del mensajero, para el que pide la muerte. Mas de nuevo Demetrio se inclina por el perdón y envía a Rudolfo otra vez con Boris.

La brevísima escena sexta (versos 2949-2972, siguen las redondillas) refleja un momento de la batalla entre los dos ejércitos. Demetrio, espada en mano, apela a los de su bando, que huyen. Rufino revela que son apenas veinte mil contra los cien mil del ejército de Boris. Pero la escena séptima y última (versos 2973-3077, endecasílabos blancos más romance en -oa) señala cómo la situación se invierte: ante el valor de Demetrio, sus huestes se rehacen. Boris aparece perseguido por él y ofrece otro momento truculento, pues se da de puñaladas para matarse, aunque sale discretamente de escena, para que oigamos: «Murió vertiendo sangre por la boca» (p. 568). No concluyen los horrores, pues un soldado narra cómo Orofrisa da un veneno a sus dos hijos y se suicida de inmediato. Queda solo el triunfo final, con las bodas del nuevo Duque de Moscovia con Margarita, secundadas por las de Rufino con Lisena, y el anuncio de la campaña contra Suecia, en la que Rusia será aliada de Polonia.

En suma, estamos ante una comedia que se sale no poco de los cánones habituales que consideramos propios del teatro de Lope de Vega. Un asunto estrictamente de actualidad, pero de historia extranjera, en un país europeo muy lejano; un protagonista cuya verdadera entidad estaba en discusión, cosa que al escritor no pudo pasarle inadvertida, aunque no reflejara la mínima duda en los versos; una despreocupación total por el aspecto que más importaba en ciertos sectores, como el Papado y los jesuitas, cual era la posibilidad de la conversión de Moscovia, que Lope ya hace territorio católico; cierto desenfado ante otros datos históricos, como el verdadero parentesco entre Demetrio y el zar Iván -Juan Basilio en la obra-. En suma, lo que parece interesarle es ante todo el despliegue de una acción extraordinariamente movida, con escenas de brutalidad indudable, para representar el trayecto de un hombre desde los riesgos que acechan su vida en la niñez hasta el triunfo final con la corona en sus sienes. Ahora bien ello tampoco es aprovechado para obtener reflexiones éticas acerca de la volubilidad de la fortuna, lo efímero de todo poder o la recompensa de la virtud. Lope de Vega está lejos de querer transmitir ninguna moraleja y parece preocupado tan solo por construir una obra que atraiga al público por su acción y a veces por una truculencia algo sorprendente. 


\section{BIBLIOGRAFÍA}

Bavia, Luis de, Tercera parte de la Historia Pontifical y Católica, Madrid, Luis Sánchez, 1608.

Bavia, Luis de, Cuarta Parte de la Historia Pontifical, y Catolica, Madrid, Luis Sánchez, 1613.

Brody, Ervin C., The Demetrius Legend and its Literary Treatment in the Age of the Baroque, Cranbury, NJ, Associated University Presses, 1972.

Bruerton, Courtney, «Lope's Belardo-Lucinda Plays», Hispanic Review, 5, 1937, pp. 309-315.

Canonica, Elvezio, «De l'histoire fictive à la fiction historique. Le cas de El Gran Duque de Moscovia de Lope de Vega», Colloquium Helveticum, 20, 1994, pp. $97-$ 115.

Castro, Américo, «Alusiones a Micaela de Luján en las obras de Lope de Vega», Revista de Filología Española, 5, 1918, pp. 256-292.

Castro, Américo y Hugo A. Rennert, Vida de Lope de Vega, Salamanca, Anaya, 1968.

Crivellari, Daniele, «¿Las relaciones piden los romances? Métrica y narración en dos comedias de Lope de Vega (1610)», Anuario Lope de Vega, 21, 2015, pp.1-28.

Di Pastena, Enrico, «La Séptima Parte: historia editorial», en Vega, 2008, I, pp. 9-59.

Fichter, William L., «Notes on the Chronology of Lope de Vega's Comedias», Modern Language Notes, 39, 1924, pp. 268-275.

García Reidy, Alejandro, «Notas a un problema de repertorios teatrales (Lope de Vega, Pinedo y el difunto Vergara)», en En Teoría hablamos de Literatura. Actas del III Congreso Internacional de Aleph, ed. Antonio César Morón Espinosa y José Manuel Ruiz Martínez, Granada, Dauro, 2007, pp. 462-468.

García Reidy, Alejandro, Las musas rameras. Oficio dramático y conciencia profesional en Lope de Vega, Madrid/Frankfurt, Iberoamericana/Vervuert, 2013.

González Palencia, Ángel, «Pleito entre Lope de Vega y un editor de sus comedias», Boletín de la Biblioteca Menéndez Pelayo, 3, 1921, pp. 17-26.

Menéndez Pelayo, Marcelino, Estudios sobre el teatro de Lope de Vega, Santander, CSIC, vol. II, 1949.

Mosquera, Juan, Relación de la señalada y como milagrosa conquista del paterno Imperio, conseguida del Serenísimo Príncipe Juan Demetrio, Gran Duque de Moscovia, en el año de 1605, Valladolid, Andrés de Merchán, 1606.

Morley, S. Griswold, y Courtney Bruerton, The Chronology of Lope de Vega's Comedias, New York, The Modern Language Association of America, 1940.

Morley, S. Griswold, y Courtney Bruerton, Cronología de las comedias de Lope de Vega, Madrid, Gredos, 1968. 
Paz y Mélia, Antonio, Catálogo de las pìezas de teatro que se conservan en el Departamento de manuscritos de la Biblioteca Nacional, Madrid, 1934, $2^{\text {a }}$ ed.

Poehl, Gertrud V., «La fuente de El Gran Duque de Moscovia de Lope de Vega», Revista de Filología Española, 19, 1932, pp. 47-63.

Praag, J. A. van, «Más noticias sobre la fuente de El Gran Duque de Moscovia de Lope de Vega», Bulletin Hispanique, 39, 1937, pp. 356-366.

Rozas, Juan Manuel, Significado y doctrina del «Arte nuevo» de Lope de Vega, Madrid, SGEL, 1976.

Smotki, Eugenia, «El mundo ruso en una comedia de Lope de Vega: la manipulación literaria», en Los extranjeros en la España moderna. Actas del I Coloquio Internacional, ed. M. ${ }^{a}$ Begoña Villar García y Pilar Pezzi Cristóbal, Málaga, 2003, vol. II, pp. 721-735.

Vega, Lope de, Comedias escogidas, ed. Juan Eugenio de Hartzenbusch, Madrid, BAE, vol. IV, 1860.

Vega, Lope de, Obras, ed. Marcelino Menéndez Pelayo, Madrid, Real Academia Española, vol VI, 1896.

Vega, Lope de, Comedias. Parte VII, coord. Enrico di Pastena, Lleida, Milenio, 2008, 3 vols.

Vernet, J., «Las fuentes de El Gran Duque de Moscovia», Cuadernos de Literatura, 5-6, 1949, pp. 17-36.

Weiner, Jack, «Un episodio de la historia rusa visto por autores españoles del Siglo de oro. El pretendiente Demetrio», Journal of Hispanic Philology, 2, 3, 1978, pp. 175-201.

Wilkinson, Alexander S. y Alejandra Ulla Lorenzo (ed.), Iberian Books 1601-1650/ Libros Ibéricos 1601-1650, Leiden, Brill, 2015, vols. II y III del Proyecto Iberian Books. 
